Supplement of Geosci. Model Dev., 12, 1491-1523, 2019

https://doi.org/10.5194/gmd-12-1491-2019-supplement

(C) Author(s) 2019. This work is distributed under

the Creative Commons Attribution 4.0 License.

(c) (1)

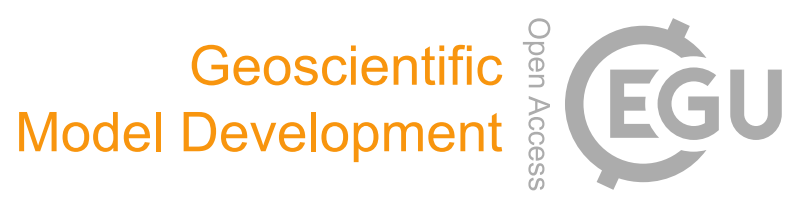

Supplement of

\title{
Ocean carbon and nitrogen isotopes in CSIRO Mk3L-COAL version 1.0: a tool for palaeoceanographic research
}

Pearse J. Buchanan et al.

Correspondence to: Pearse J. Buchanan (pearse.buchanan@liverpool.ac.uk)

The copyright of individual parts of the supplement might differ from the CC BY 4.0 License. 
2 - Figure S1: Zonal mean observed (top) and UVic-MOBI modelled (bottom) $\delta^{13} \mathrm{C}$ of DIC for each major basin.

3 - Figure S2: Zonal mean observed (top) and PISCES modelled (bottom) $\delta^{13} \mathrm{C}$ of DIC for each major basin.

$4 \quad$ - Figure S3: Zonal mean observed (top) and LOVECLIM modelled (bottom) $\delta^{13} \mathrm{C}$ of DIC for each major basin.

5 - Figure S4: Zonal mean observed (top) and iCESM-low modelled (bottom) $\delta^{13} \mathrm{C}$ of DIC for each major basin.

6 Figure $\mathbf{S 1}$ 
Figure S1. Zonal mean observed (top) and UVic-MOBI modelled (bottom) $\delta^{13} \mathrm{C}$ of DIC for each major basin. The red dashed line marks the upper 175 metres and is used for comparison between observed and modelled distributions.
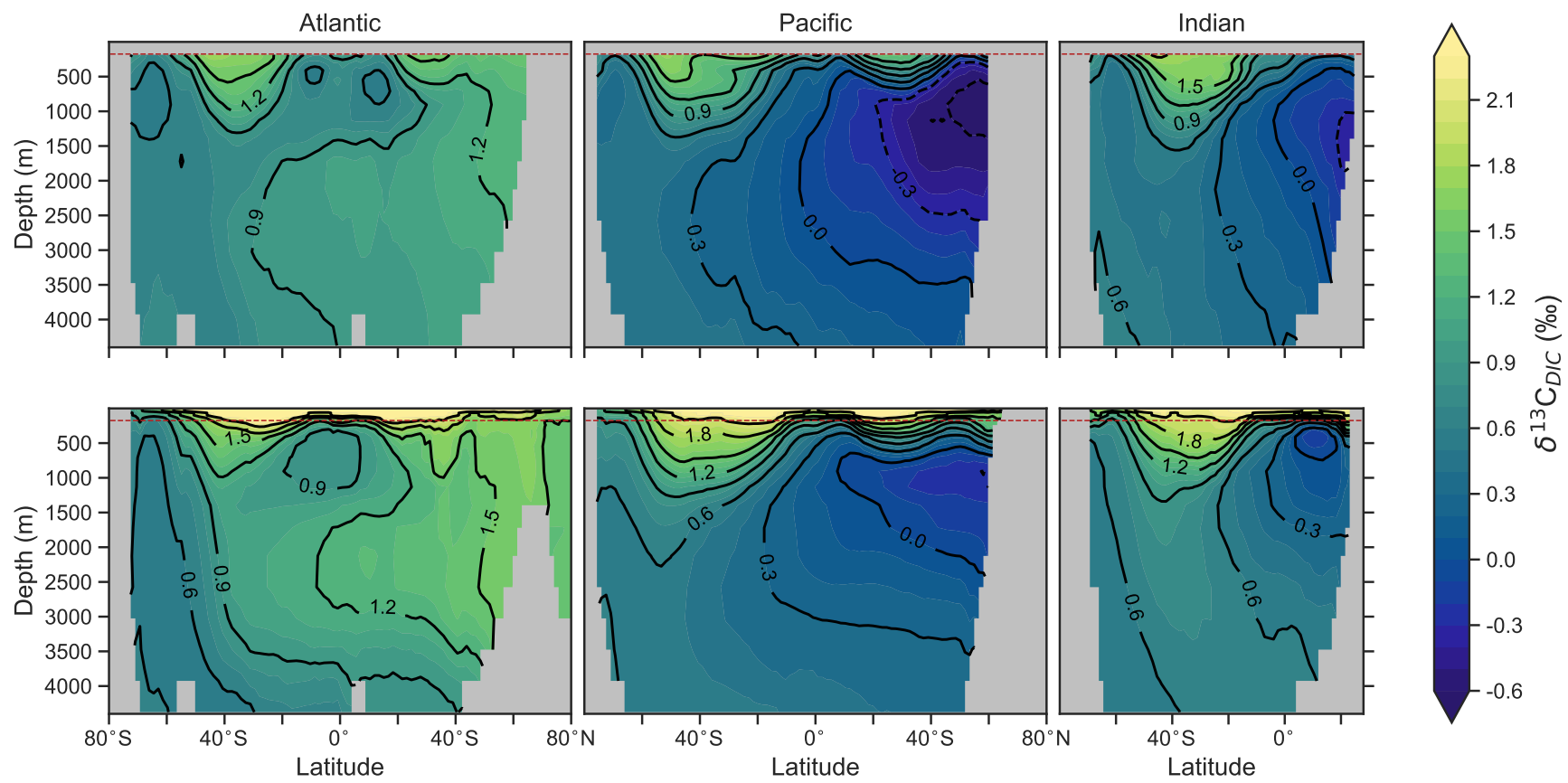

\section{$1 \quad$ Figure $\mathbf{S 2}$}


Figure S2. Zonal mean observed (top) and PISCES modelled (bottom) $\delta^{13} \mathrm{C}$ of DIC for each major basin. The red dashed line marks the upper 175 metres and is used for comparison between observed and modelled distributions.
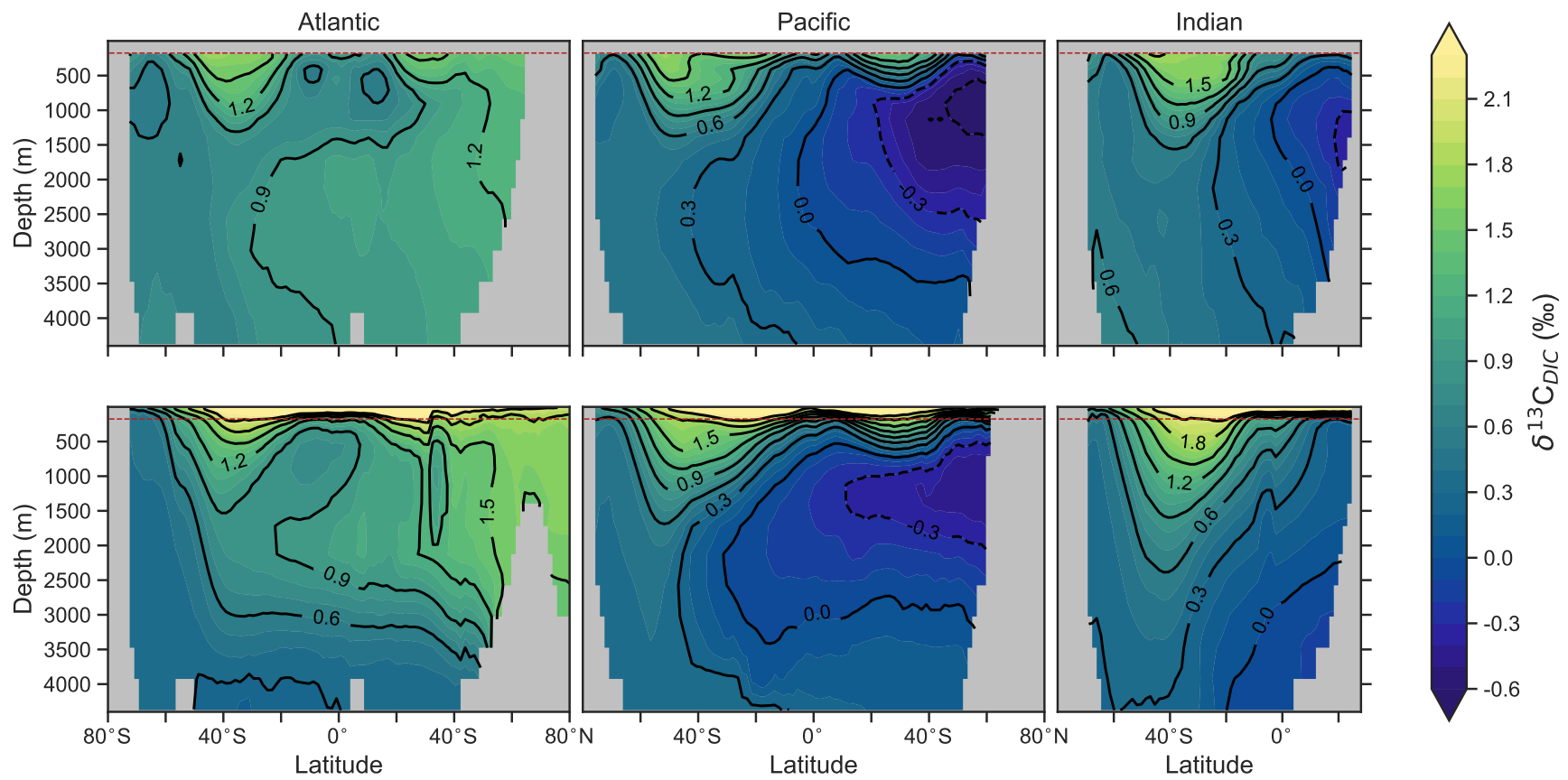

\section{Figure $\mathbf{S 3}$}


Figure S3. Zonal mean observed (top) and LOVECLIM modelled (bottom) $\delta^{13} \mathrm{C}$ of DIC for each major basin. The red dashed line marks the upper 175 metres and is used for comparison between observed and modelled distributions.
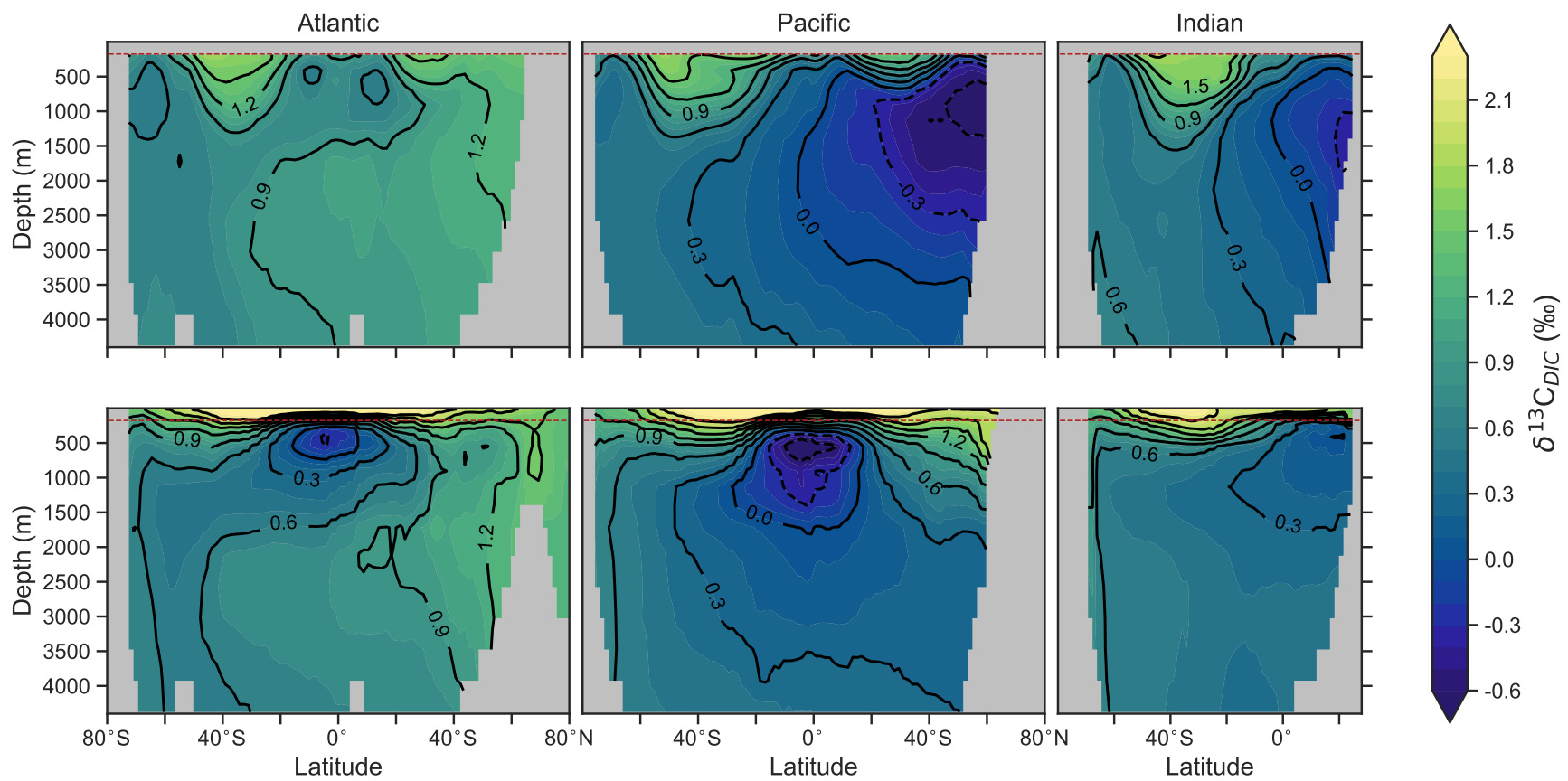

\section{$1 \quad$ Figure $\mathbf{S 4}$}


Figure S4. Zonal mean observed (top) and iCESM-low modelled (bottom) $\delta^{13} \mathrm{C}$ of DIC for each major basin. The red dashed line marks the upper 175 metres and is used for comparison between observed and modelled distributions.

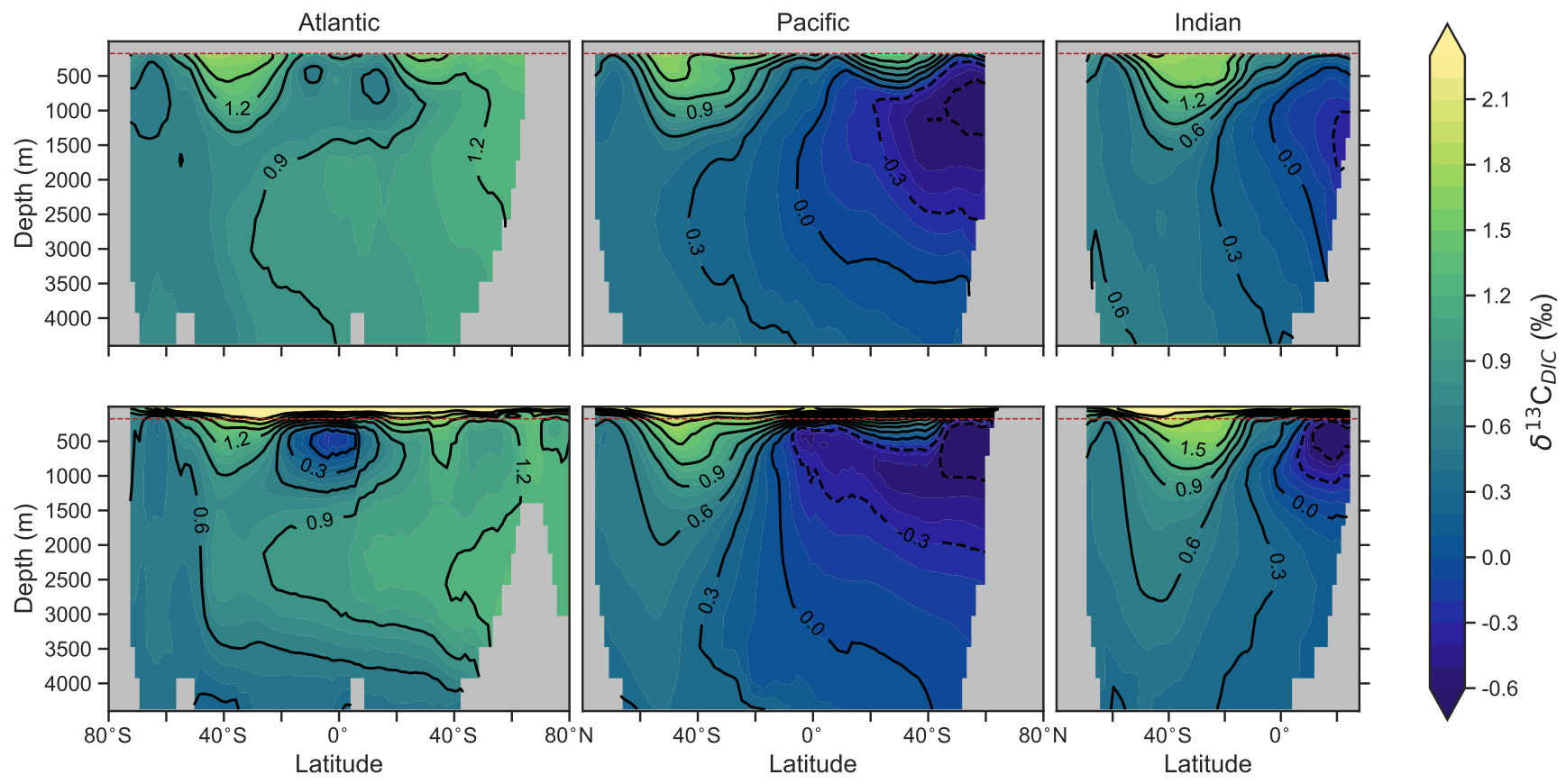

